\title{
Screening of Threading Bis-Intercalators Binding to Duplex DNA by Electrospray Ionization Tandem Mass Spectrometry
}

\author{
Carolyn L. Mazzitelli, Yongjun Chu, Joseph J. Reczek, Brent L. Iverson, \\ and Jennifer S. Brodbelt \\ Department of Chemistry and Biochemistry, University of Texas at Austin, Austin, Texas, USA
}

The DNA binding of novel threading bis-intercalators V1, trans-D1, and cis-C1, which contain two naphthalene diimide (NDI) intercalation units connected by a scaffold, was evaluated using electrospray ionization mass spectrometry (ESI-MS) and DNAse footprinting techniques. ESI-MS experiments confirmed that V1, the ligand containing the -Gly ${ }_{3}$-Lys- peptide scaffold, binds to a DNA duplex containing the 5'-GGTACC-3' specific binding site identified in previous NMR-based studies. The ligand formed complexes with a ligand/DNA binding stoichiometry of 1:1, even when there was excess ligand in solution. Trans-D1 and cis-C1 are new ligands containing a rigid spiro-tricyclic scaffold in the trans- and cis- orientations, respectively. Preliminary DNAse footprinting experiments identified possible specific binding sites of $5^{\prime}$-CAGTGA-5' for trans-D1 and 5'-GGTACC-3' for cis-C1. ESI-MS experiments revealed that both ligands bound to DNA duplexes containing the respective specific binding sequences, with cis-C1 exhibiting the most extensive binding based on a higher fraction of bound DNA value. Cis-C1 formed complexes with a dominant 1:1 binding stoichiometry, whereas trans-D1 was able to form 2:1 complexes at ligand/DNA molar ratios $\geq 1$ which is suggestive of nonspecific binding. Collisional activated dissociation (CAD) experiments indicate that DNA complexes containing V1, trans-D1, and cis-C1 have a unique fragmentation pathway, which was also observed for complexes containing the commercially available bis-intercalator echinomycin, as a result of similar binding interactions, marked by intercalation in addition to hydrogen bonding by the scaffold with the DNA major or minor groove. (J Am Soc Mass Spectrom 2007, 18, 311-321) (c) 2007 American Society for Mass Spectrometry

$\mathrm{M}$ any anticancer, antitumor, and antibacterial therapies are based on the interaction of small molecules with DNA [1, 2], fostering the need for sensitive and versatile analytical techniques that are both capable of characterizing the ligand/DNA interactions and compatible with library-based screening methods. Electrospray ionization mass spectrometry (ESI-MS) shows promise as a screening tool for the evaluation drug/DNA complexes due to its low sample consumption and rapid analysis time [3,4]. During the electrospray process, noncovalent complexes are transferred to the gas phase with minimal internal energy, allowing many of the binding interactions to be maintained. The preservation of these noncovalent complexes allows information about binding stoichiometry and selectivity to be elucidated from the mass spectra, while tandem mass spectrometry techniques, such as collisional activation dissociation (CAD), can be used to examine the binding mode.

Published online November 13, 2006

Address reprint requests to Dr. J. S. Brodbelt, Department of Chemistry and Biochemistry, University of Texas at Austin, 1 University Station A5300, Austin, TX 78712-0165, USA. E-mail: jbrodbelt@mail.utexas.edu
One important class of DNA-interactive drugs are ligands that bind via intercalation of one or more aromatic groups between base pairs of duplex DNA [1, $2,5]$. There have been numerous ESI-MS studies that have examined the interaction between duplex DNA and well-studied, commercially available mono-intercalators such as the anthracyclines [6-11], porphyrins [12, 13], ruthenium compounds [11-15], ethidium bromide [16-18], actinomycin-D [12, 13], and aureolic acids [19]. Characteristics such as ligand binding stoichiometry [7, 8, 11-14, 16, sequence selectivity [7, 11, 13, 14, 16, 19], binding mode $[12,13,15]$, and complex stability $[9,12$, 16] have been examined with promising results correlating the binding trends observed in the mass spectra to known solution behavior. While the binding of many commercial mono-intercalators has been well-studied by ESI-MS, there has been only one study [20] that has focused on a bis-intercalator, ditercalinium. Based on ESI-MS measurements of the complexation of ditercalinium to a series of DNA sequences, it was found that ditercalinium bound better to quadruplex structures than to duplexes [20].

The development of novel polyintercalating ligands is of interest because of the potential improvements in 


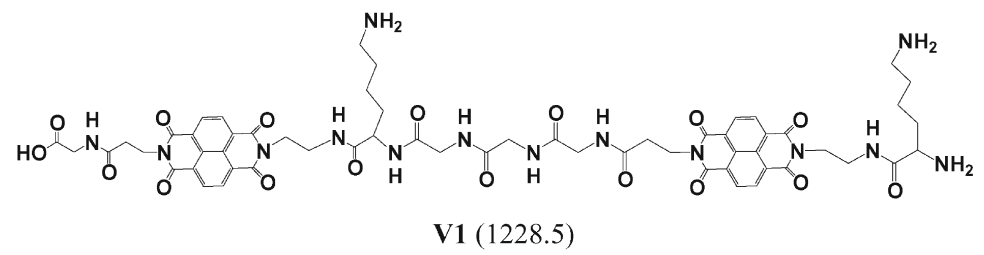

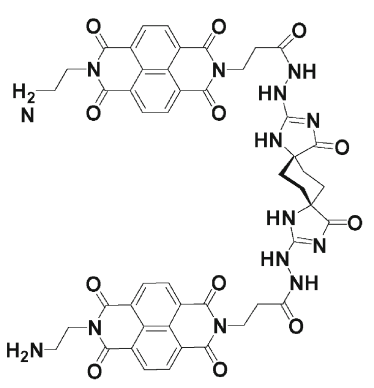

cis-C1 (1006.3)

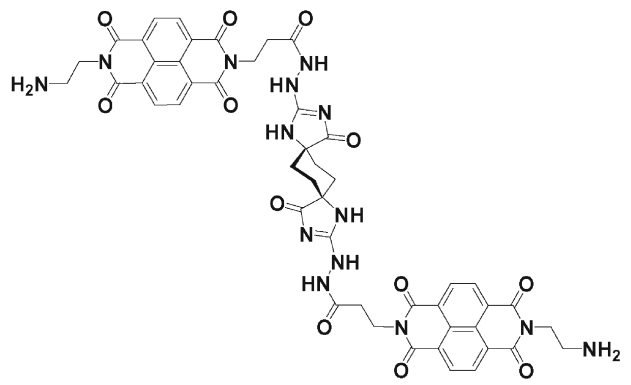

trans-D1 (1006.3)

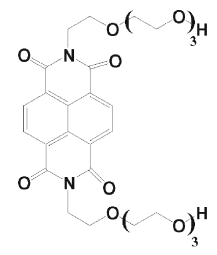

NDI1 (618.2)
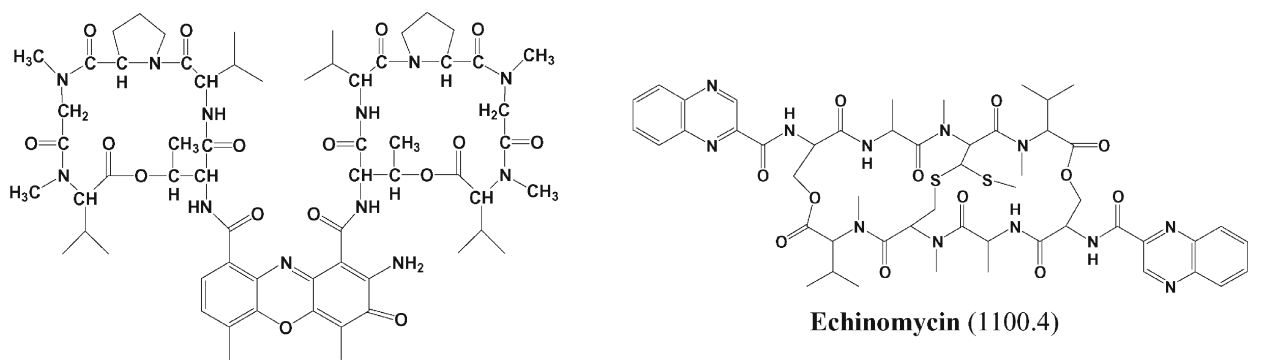

Echinomycin (1100.4)

Actinomycin-D (1254.6)

Scheme 1. Structures of intercalator ligands. Molecular weights of compounds in Da are given in parenthesis.

antitumor activity and sequence specificity. A novel class of DNA polyintercalators that shows great promise for binding to long stretches of DNA with sequence specificity and high affinity contain 1,4,5,8-tetracarboxylic naphthalene diimide (NDI) units connected in a head-to-tail arrangement by flexible scaffolds [21-24] (see Scheme 1). These compounds are known as threading polyintercalators because, upon intercalation, one of the functional groups attached to the diimide nitrogen resides in the DNA major groove, while the other is in the minor groove [21]. The potential advantages of developing a compound that binds to duplex DNA by threading polyintercalation include enhanced sequence specificity due to ligand interactions with the major and minor groove, the ability to bind to longer DNA sequences with a relatively low molecular weight compound, disruption of protein-ligand interactions that occur in both DNA grooves, and lower binding off-rates [22].

A series of bis-intercalators, compounds that contain two NDI units, have been synthesized as precursors to longer compounds with more than two intercalation groups (Scheme 1). The primary objective of this study is to evaluate the binding behavior of trans-D1 and cis-C1, which are new ligands containing a rigid spiro- tricyclic scaffold in the trans- and cis- orientations, respectively. While few results have been reported for the newer ligands trans-D1 and cis-C1 [25], the binding behavior of V1, the ligand containing the peptide scaffold, has been examined in extensive footprinting and NMR-based studies $[22,23]$. In the present study, the binding behavior of the well-characterized compound V1 will be examined to establish that the binding behavior observed by ESI-MS can be correlated to the results of traditional solution-based experiments. After developing a framework with $\mathbf{V 1}$, the binding of the new compounds, trans-D1 and cis-C1, will be reported with an emphasis on comparing differences in binding behavior of the compounds that result from the transversus cis orientations of the scaffold. Here, we examine binding stoichiometries, sequence selectivities, and concentration dependent binding of the bis-intercalators, evaluate the CAD fragmentation patterns of the observed DNA/drug complexes, and compare the results to ones obtained by conventional footprinting techniques. The binding of the bis-intercalator, echinomycin (Scheme 1) was also assessed by ESI-MS to serve as a comparison to the results of $\mathbf{V 1}$, cis-C1, and trans-D1. We also will compare the results of our study with other ESI-MS based studies involving mono-intercalators. 
Table 1. DNA sequences used in this study

\begin{tabular}{llc}
\hline Name & \multicolumn{1}{c}{ Sequence } & Molecular Weight (Da) \\
\hline \hline ds1 & d(GGGCGGTACCGCGG/CCGCGGTACCGCCC) & 8531.5 \\
ds2 & d(GCGGGGATGGGCG/CGCCCCATCCCCGC) & 8531.6 \\
ds3 & d(GCGGGATTGGGCG/CGCCCAATTCCGC) & 8529.6 \\
ds4 & d(GCGGAAATTGGCG/CGCCAAATTTCCGC) & 8527.7 \\
ds5 & d(GGGACAGTGAGGGG/CCCCTCACTGTCCC) & 8529.6 \\
ds6 & d(GGTTGGGCCCAAGG/CCTTGGGCCCAACC) & 8529.6 \\
ds7 & d(GGGGTCGCCGGGG/CCCCCGGCGACCCC) & 8532.6 \\
\hline
\end{tabular}

Another objective of this study is to demonstrate that mass spectrometry can be used as a screening tool for bis-intercalator ligands. To accomplish this aim, we demonstrate that the ESI-MS results mirror those established by traditional techniques such as NMR and DNAse I footprinting experiments to lend legitimacy to ESI-MS as an analysis tool for future studies involving novel polyintercalating compounds. It is not anticipated that ESI-MS will replace traditional techniques such as NMR and DNAse I footprinting, but instead that it be used as an initial screening tool. As drug discovery efforts shift to combinatorial synthesis of compound libraries, ESI-MS is suited to narrow down the pool of promising ligands that would then be examined in more detail using traditional methods.

\section{Experimental}

\section{Chemicals}

Single strand oligodeoxynucleotides (ODNs), custom synthesized as ammonium salts on the $1.0 \mu \mathrm{mol}$ or 250 nmol scale with purification by HPLC, were obtained from Integrated DNA Technologies (Coralville, IA) and used without further purification. Stock solutions of each ODN were prepared at $2 \mathrm{mM}$ concentration in deionized water. A portion of the stock solutions were diluted to $1 \mathrm{mM}$ and set aside for experiments involving single strand ODNs. Duplex DNA was annealed by preparing solutions containing two complementary single strand ODNs, each at $0.7 \mathrm{mM}$ concentration in 250 $\mathrm{mM}$ ammonium acetate. The annealing solutions were heated to $90^{\circ} \mathrm{C}$ and then slowly cooled over a period of $4 \mathrm{~h}$. Table $1{ }^{\circ}$ shows the ${ }^{\circ}$ sequences used in this study. The synthesis ${ }^{\circ}$ of $^{\circ}$ ligands $^{\circ} \mathbf{V 1}$ [26], ${ }^{\circ}$ trans-D1 [25], ${ }^{\circ}$ cis-C1 [25], and ${ }^{\circ} \mathrm{NDI} 1^{\circ}[27]^{\circ}{ }^{\circ}$ ave ${ }^{\circ}$ been ${ }^{\circ}$ previously ${ }^{\circ}$ reported..$^{\circ}$ Concentrations were determined spectroscopically using Beer's law. The extinction coefficients for the DNA strands were provided by the manufacturer and those of the ligands are $26300 \mathrm{M}^{-1} \mathrm{~cm}^{-1}(385 \mathrm{~nm})$ for cis-C1, 36,000 $\mathrm{M}^{-1} \mathrm{~cm}^{-1}$ (383 nm) for trans-D1, and $26300 \mathrm{M}^{-1} \mathrm{~cm}^{-1}$ $\left(385^{\circ} \mathrm{nm}\right)^{\circ}$ for ${ }^{\circ} 1^{\circ}[25]$.

\section{DNAse I Footprinting}

Plasmid pBR322 (New England BioLabs, Ipswich, MA) was digested with NheI, dephosphorylated with CIAP, $5^{\prime}-{ }^{32} \mathrm{P}-\mathrm{end}$ labeled with $\left[\gamma^{32} \mathrm{P}\right]-\mathrm{ATP}$ and T4 kinase, digested with EcoRI (all enzymes were purchased from New England Biolabs) and purified by native polyacrylamide gel electrophoresis (PAGE), following standard protocols ${ }^{\circ}[28] . .^{\circ}$ The $^{\circ} 92^{\circ}$ bp $^{\circ}$ synthetic $^{\circ}$ fragment $^{\circ}(\mathrm{PAGE}$ grade) was purchased from Midland Certified and labeled $\left({ }^{32} \mathrm{P}\right)$ similarly. The DNAse I (Amersham) footprinting was carried out according to the procedure described ${ }^{\circ}$ previously $^{\circ}[29]^{\circ} .^{\circ}$ The $^{\circ} \mathrm{DNA}^{\circ}$ fragments ${ }^{\circ}$ were separated on an $8 \%$ (231 bp) or 12\% (92 bp) denaturing polyacrylamide gel. The gels were exposed on phosphor screen and analyzed with Quantity One 4.5 software from Bio-Rad (Hercules, CA).

\section{Mass Spectrometry}

Stock solutions of V1, trans-D1 and cis-C1 were prepared in deionized water at $1 \mathrm{mM}$. Analytical solutions containing duplex or single strand DNA and one ligand were prepared at equimolar $10 \mu \mathrm{M}$ concentration (unless noted otherwise) in $50 \mathrm{mM}$ ammonium acetate with $25 \%$ methanol to enhance the volatility of the solution. Lower concentrations of methanol result in similar binding trends, but the quality of the ESI-mass spectra is diminished. After allowing the solutions to equilibrate for $30 \mathrm{~min}$., they were directly infused into a ThermoFinnigan LCQ Duo mass spectrometer (San Jose, CA) using a Harvard syringe pump (Holliston, $\mathrm{MA})$ at $3 \mu \mathrm{L} / \mathrm{min}$. Ions were generated in the negative ion mode with an electrospray voltage of $3.5 \mathrm{kV}$. The temperature of the heated capillary was set at 90 to $110^{\circ} \mathrm{C}$ and nitrogen sheath and auxiliary gas flows of 10 and 40 arbitrary units, respectively, were used to aid in desolvation. The base pressure in the ion trap region was nominally $\sim 1 \times 10^{-5}$ torr. Instrument conditions were optimized for each complex using the automatic tuning function of the Xcalibur software package (Finnigan, San Jose, CA). Spectra were acquired by summing 300 scans with an ion accumulation time of $100 \mathrm{~ms}$.

Tandem mass spectrometry experiments were performed using collisional activated dissociation (CAD). The desired precursor ion was isolated in the trap using resonance ejection, followed by fragmentation induced by increasing the resonance voltage applied to the trap. An activation time of $30 \mathrm{~ms}$ was used for all experiments. The CAD energy was increased until the abundance of the precursor ion was reduced to $\sim 10 \%$ 
relative abundance. These experiments required CAD energies of $\sim 12$ to $14 \%$.

\section{Results and Discussion}

\section{Complexes with $V 1$}

The DNA binding of ligand V1 has been previously examined by NMR and DNAse I footprinting techniques that identified the specific binding sites of this compound $^{\circ}[23]^{\circ}{ }^{\circ}$ V1 was $^{\circ}$ found ${ }^{\circ}$ to $^{\circ}$ have $^{\circ} a^{\circ}$ binding preference for d(GGTACC) ${ }_{2}$ sequences with NMR results confirming that the -Gly ${ }_{3}$-Lys- peptide scaffold was $^{\circ}$ located $^{\circ}$ in $^{\circ}$ the ${ }^{\circ}$ major $^{\circ}$ groove $^{\circ}[23] .^{\circ}{ }^{\circ}$ The $^{\circ}$ V1-d(GGTACC $)_{2}$ complex was formed with a dominant 1:1 binding stoichiometry.

The binding of V1 to a DNA duplex containing the preferred binding sequence was evaluated by ESI-MS to confirm that results revealed in the mass spectra can be correlated to the solution binding behavior. The 14-mer d(GGGCGGTACCGCGG/CCGCGGTACCGCCC) (ds1) was used for this study because it contains the specific binding sequence of V1 (GGTACC). All of the duplex DNA sequences selected for this study were non-selfcomplementary to allow the duplex and single strand ions to be unambiguously distinguished in the mass spectra. Duplexes with 14 base pairs were selected for this study because previous ion mobility/molecular dynamics studies have reported that DNA duplexes greater than 12 base pairs better maintain the helical conformations in the gas-phase $^{\circ}$ than $^{\circ}$ smaller $^{\circ}$ duplexes ${ }^{\circ}\left[30,{ }^{\circ} 31\right]^{\circ}{ }^{\circ}$ Even ${ }^{\circ}$ larger duplexes were not chosen to ensure that there was only one high affinity binding site per duplex, allowing different binding sequences to be assessed individually. Each duplex was designed to contain the proposed high affinity ligand binding site in the center of the sequence. The terminal ends of the duplexes were selected to be G/C rich to enable good annealing of the sequences, and the sequences directly adjacent to the proposed specific binding site were selected based on the flanking sequences identified in DNAse I footprinting experiments to maintain consistency.

ESI mass spectra of solutions containing $10 \mu \mathrm{M}$ V1 and $10 \mu \mathrm{M}$ ds1 in an ammonium acetate/methanol buffer were evaluated first. Both the 5- and 6- charge states are prominent for the duplex/V1 complexes. For a typical solution containing V1 and ds1, the only complexes present in the spectrum possess a ligand/ DNA binding stoichiometry of 1:1 with 2:1 complexes being at less than $5 \%$ of the relative abundance of the 1:1 complexes.

Concentration-dependent binding studies were undertaken to examine the extent of complexation changes as a result of varying the ligand/DNA ratios. Solutions containing ds1 at $10 \mu \mathrm{M}$ and either 2.5, 5.0, 10 , or $20 \mu \mathrm{M}$ V1 were analyzed by ESI-MS (spectra not shown). As the ligand/DNA molar ratio was increased, the relative ion abundance of the 1:1 complexes in the 5- and 6- charge states increased, while that of the free duplex decreased. However, no 2:1 complexes emerged, even with excess ligand in solution. While it is possible that there are multiple sites on the duplexes for which V1 could bind to form 2:1 complexes, binding of $\mathbf{V} \mathbf{1}$ at a second site is not anticipated to be as strong because the ligand bound at the high affinity site, GGTACC, would cover six base pairs and thus presumably hinder the bis-intercalative binding of a second ligand. These results are consistent with solution-based studies of V1 $[23]^{\circ}$ and $^{\circ}$ suggest $^{\circ}$ ESI-MS $^{\circ}$ is $^{\circ} \mathrm{a}^{\circ}$ promising $^{\circ}$ tool for the analysis of DNA complexes containing bis-intercalators.

\section{Binding Selectivities of trans-D1 and cis-C1}

To explore the effect of the scaffold on the binding specificity of the polyintercalators, two new bis-intercalators, trans-D1 and cis-C1 were synthesized containing a rigid spiro-tricyclic scaffold (Scheme 1). As shown in Scheme 1, trans-D1 is a trans-oriented ligand, while cis-C1 is cis-oriented. While the design and synthesis of these ${ }^{\circ}$ compounds $^{\circ}$ has $^{\circ}$ been $^{\circ}$ previously $^{\circ}$ reported $^{\circ}[25]$, less is known about the DNA duplex binding of these compounds. We aimed to compare the binding of these compounds in a mass spectrometry based study.

To begin an ESI-MS evaluation of the binding behavior of trans-D1 and cis-C1, the complexation of each ligand with DNA duplexes containing varying A-T and G-C base pair composition was evaluated. The NDI intercalator unit has exhibited a preference for G-G steps $^{\circ}[23]^{\circ}{ }^{\circ} \mathrm{so}^{\circ}$ it $^{\circ}$ was $^{\circ}$ of $^{\circ}$ interest ${ }^{\circ}$ to $^{\circ}$ assess ${ }^{\circ}$ the ${ }^{\circ}$ binding selectivities of the new compounds. ESI mass spectra were obtained for solutions containing trans-D1 or cis-C1 with a series of three duplexes with varying amounts of G/C and A/T base pair content: d(GCGGGGATGGGGCG/CGCCCCATCCCCGC) (ds2), d(GCGGGAATTGGGCG/CGCCCAATTCCCGC) (ds3), and d(GCGGAAATTTGGCG/CGCCAAATTTCCGC) (ds4).

While both ligands exhibited GC base pair selectivity, the preference was more pronounced for transD1. ${ }^{\circ}$ As ${ }^{\circ}$ shown ${ }^{\circ}$ in $^{\circ}$ Figure $^{\circ} 1 \mathrm{a},{ }^{\circ}$ trans-D1 readily $^{\circ}$ forms abundant complexes with ds2, with ligand/DNA binding stoichiometries of 2:1 and 1:1, and little unbound DNA is present in the spectrum. The mass spectrum ${ }^{\circ}$ of $^{\circ}$ trans-D 1 with $^{\circ} \mathrm{ds}^{\circ} 3^{\circ}$ (Figure $1 \mathrm{~b}$ ) ${ }^{\circ}$ shows ${ }^{\circ}$ that the relative abundance of the 2:1 complexes is significantly ${ }^{\circ}$ decreased $^{\circ}$ compared $^{\circ}$ to $^{\circ}$ Figure $^{\circ} 1 a^{\circ},{ }^{\circ}$ and ${ }^{\circ}$ the abundance ${ }^{\circ}$ of $^{\circ}$ the ${ }^{\circ}$ unbound ${ }^{\circ}$ DNA $^{\circ}$ has ${ }^{\circ}$ increased..$^{\circ}$ The spectrum of trans-D1 with ds4, the duplex containing the most AT base pairs, reveals that only 1:1 complexes are present and with significantly lower abundances relative to the duplex ion present at $\mathrm{m} / z 1705$ (Figure $\left.{ }^{\circ} 1 \mathrm{c}\right) .{ }^{\circ}{ }^{A} s^{\circ}$ the $^{\circ} \mathrm{AT}^{- \text {content }^{\circ}}$ increases $^{\circ}{ }^{\circ}$ both ${ }^{\circ}$ the binding stoichiometry and relative abundance of the complexes formed between trans-D1 and the duplex decrease dramatically.

The extent of complexation was calculated by expressing the sum of the abundances of ions from 


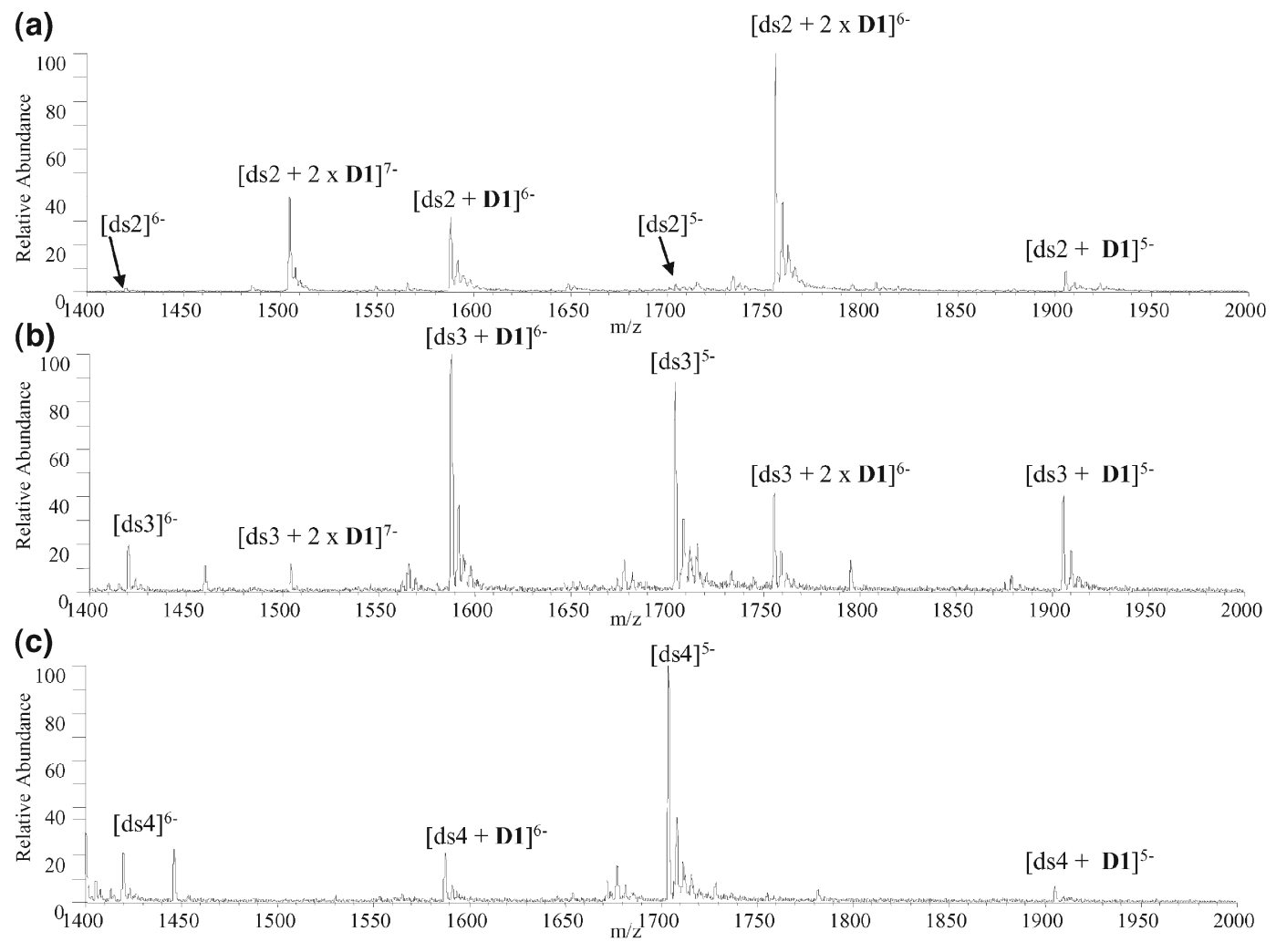

Figure 1. ESI mass spectra for complexes containing trans-D1 and equimolar $(10 \mu \mathrm{M})$ amounts of (a) ds2，d(GCGGGGATGGGGCG/CGCCCCATCCCCGC) (b) ds3， d(GCGGGAATTGGGCG/CGCCCAATTCCCGC, and (c) ds4, d(GCGGAAATTTGGCG/CGCCAAATTTCCGC).

DNA/ligand complexes as a fraction of the total abundances of all ions from DNA as has been previously

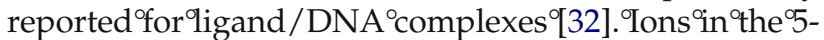
and 6- charge states were used in this calculation. The binding results for trans-D1 (discussed above) and those for cis-C1 (spectra not shown) with ds2, ds3, and ds $4^{\circ}$ are $^{\circ}$ summarized ${ }^{\circ}$ in ${ }^{\circ}$ Table $^{\circ} 2$.

Our results indicate that like trans-D1, cis-C1 also forms more abundant complexes with the GC-rich DNA duplexes, as demonstrated by a value of 0.52 for the fraction of bound DNA with ds2, compared to 0.39 with ds 3 and 0.32 with ds 4 . These results are consistent with solution dissociation kinetics experiments in which cis-C1 and trans-D1 demonstrated a strong preference for binding to poly (dGdC) over poly $^{\circ}(\mathrm{dAdT})^{\circ}$ sequences $^{\circ}[25]^{\circ} .^{\circ}$ This $^{\circ}$ is ${ }^{\circ} a^{\circ}$ trend ${ }^{\circ}$ that ${ }^{\circ}$ has been ${ }^{\circ}$ previously $^{\circ}$ reported $^{\circ}$ for $^{\circ} \mathrm{NDI}^{\circ}$ intercalation ${ }^{\circ}[21$, 33]. ${ }^{\circ}$ The $^{\circ}$ observed $^{\circ}$ poly $^{\circ} \mathrm{d}(\mathrm{GdC})^{\circ}$ preference $^{\circ}$ of ${ }^{\circ}$ the ligands may be the result of a variety of binding interactions. Increased hydrogen bonding between the intercalators and functional groups in the major and minor grooves of GC-rich sequences could account for this preference. The imide carbonyls on the NDI units may also undergo a favorable electrostatic interaction with the $\mathrm{N}^{2}$ amino group on $\mathrm{G}: \mathrm{C}$ base pairs ${ }^{\circ}[33] .{ }^{\circ}$ Steric ${ }^{\circ}$ and ${ }^{\circ}$ hydrophobic ${ }^{\circ}$ interactions ${ }^{\circ}$ could $^{\circ}$ also $^{\circ}$ play $^{\circ}$ roles $^{\circ}[21-23] .{ }^{\circ}$ While $^{\circ}$ the ${ }^{\circ}$ ligands $^{\circ}$ demon- $^{\circ}$ strate a general preference for GC-rich sequences, likely because of the NDI units, the functional linker imparts specific binding preferences.

Table 2. Fraction of bound $\mathrm{DNA}^{\mathrm{a}}$ for intercalator ligands and DNA duplexes. ${ }^{\mathrm{f}, \mathrm{g}}$

\begin{tabular}{|c|c|c|c|c|c|c|c|c|c|}
\hline & ds $1^{b, c}$ & ds2 & ds3 & ds4 & $d s 5^{d}$ & ds6 $6^{c}$ & $d s 7^{d}$ & ss1 & ss5 \\
\hline V1 & 0.66 & $n / a^{e}$ & $n / a^{e}$ & $n / a^{e}$ & 0.52 & $\mathrm{n} / \mathrm{a}^{\mathrm{e}}$ & $\mathrm{n} / \mathrm{a}^{\mathrm{e}}$ & 0.00 & $\mathrm{n} / \mathrm{a}^{\mathrm{e}}$ \\
\hline cis-C1 & 0.86 & 0.52 & 0.39 & 0.32 & 0.38 & 0.51 & $\mathrm{n} / \mathrm{a}^{\mathrm{e}}$ & 0.00 & $\mathrm{n} / \mathrm{a}^{\mathrm{e}}$ \\
\hline trans-D1 & 0.40 & 0.94 & 0.64 & 0.18 & 0.78 & $\mathrm{n} / \mathrm{a}^{\mathrm{e}}$ & 0.85 & $\mathrm{n} / \mathrm{a}^{\mathrm{e}}$ & 0.17 \\
\hline NDI1 & 0.53 & $\mathrm{n} / \mathrm{a}^{\mathrm{e}}$ & $\mathrm{n} / \mathrm{a}^{\mathrm{e}}$ & $\mathrm{n} / \mathrm{a}^{\mathrm{e}}$ & 0.41 & $\mathrm{n} / \mathrm{a}^{\mathrm{e}}$ & $\mathrm{n} / \mathrm{a}^{\mathrm{e}}$ & $\mathrm{n} / \mathrm{a}^{\mathrm{e}}$ & $\mathrm{n} / \mathrm{a}^{\mathrm{e}}$ \\
\hline
\end{tabular}

all values $+/-0.05$. This value was calculated to be the greatest standard deviation for the results of three experiments done with the samples. bequence contains proposed binding site of $\mathbf{V} \mathbf{1}$.

'Sequence contains proposed binding site of cis-C1.

${ }^{\mathrm{d}}$ Sequence contains proposed binding site of trans-D1.

" $n / a$ " indicates data was not collected because the results were not relevant to the study.

fSolutions contained equimolar $(10 \mu \mathrm{M})$ concentrations of ligand and DNA.

9The abundances for all of the sodium adducts associated with a complex were included in the relative abundance calculations. 


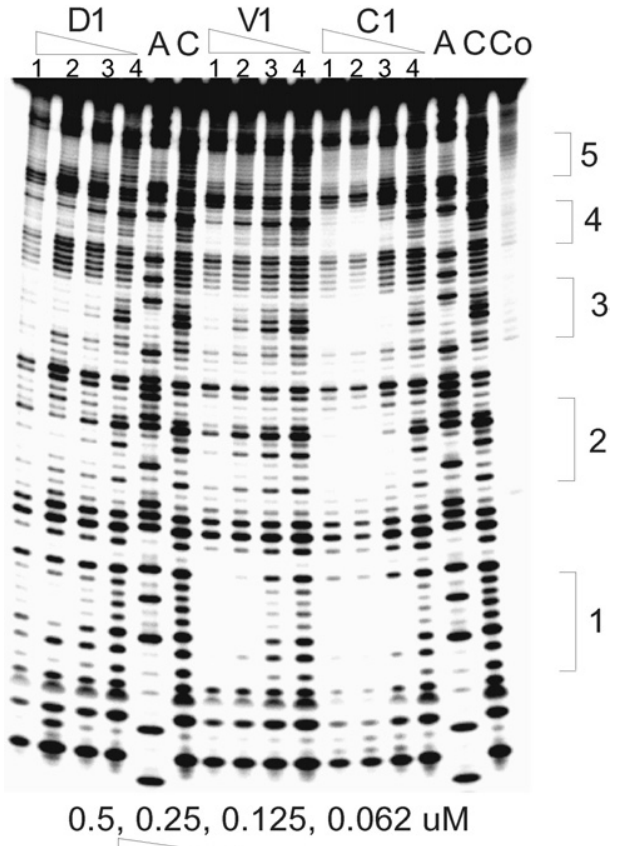

Figure 2. Footprinting of compounds cis-C1, trans-D1, and V1 on 92 mer DNA with the $(-)$ strand labeled on its $5^{\prime}$-end. Lane A represents Adenine-specific sequencing reaction. Lane Co contains DNA without DNAse I. For D1, V1, and C1, lanes 1-4 contain $0.5,0.25,0.125$, and $0.062 \mu \mathrm{M}$ ligand, respectively. Lane $\mathrm{C}$ contains DNA with DNAse but no compound. Sequences at 1 : 5'-GGTACC; 2: 5'-GGATCC; 3: 5'-GGGCCC; 4: 5'-GGCGCC; 5: $5^{\prime}$-GGGGCC.

\section{DNAse I Footprinting}

In addition to evaluating the GC versus AT sequence selectivity of trans-D1 and cis-C1, the binding of the compounds to duplexes containing potential specific binding sites was also evaluated by DNAse I footprinting and ESI-MS. It has been established that the naphthalenetetracarboxylic diimide based intercalator units possess ${ }^{\circ} \mathrm{a}^{\circ}$ preference ${ }^{\circ}$ for ${ }^{\circ}$ binding ${ }^{\circ} \mathrm{G}-\mathrm{G}^{\circ}$ steps $^{\circ}[23]^{\circ}{ }^{\circ}$ To investigate the specificity of binding, DNAse I footprinting studies with trans-D1, cis-C1 and reference ligand V1 were carried out using a synthetic $92 \mathrm{bp}$ DNA fragment ${ }^{\circ}$ containing ${ }^{\circ} 5^{\circ} 5^{\prime}$-GGNNCC- $3^{\prime}{ }^{\circ}$ sites $^{\circ}$ (Figure ${ }^{\circ}$ ). As reported previously, $\mathbf{V} \mathbf{1}$ has a distinct binding site at 5'-GGTACC-3' with a $\mathrm{K}_{\mathrm{d}^{\circ}} \sim 100^{\circ} \mathrm{nM}^{\circ}[23]$.

trans-D1 showed some non-specific binding behavior, from targeting less than six-base pairs to only binding ${ }^{\circ}$ at $^{\circ}$ high $^{\circ}$ concentration $^{\circ}\left(>0.25^{\circ} \mu \mathrm{M}\right)^{\circ}$ (Figure $^{\circ}$ ). cis-C1, however, shows very different binding characteristics from the others. It not only binds to GGTACC with an even higher affinity than V1, but it also binds to other sequences with good affinity, such as GGGCCC and GGATCC. The variety of binding sites with good binding affinity $\left(\mathrm{K}_{\mathrm{d}} \sim 100 \mathrm{nM}\right)$ demonstrates the potential of spiro-tricyclic scaffold as a "universal" scaffold for polyintercalators.

To further investigate the binding specificity of transD1, a 231 bp EcoRI-NheI restriction fragment of plasmid
pBR322 was chosen for a second round of footprinting experiments. This sequence was previously used to screen $^{\circ}$ the ${ }^{\circ}$ binding $^{\circ}$ specificity ${ }^{\circ}$ of $^{\circ} \mathrm{NDI}^{\circ}$ ligands $^{\circ}[23]^{\circ}{ }^{\circ} \mathbf{V 1}$ was used as a reference compound. As expected, one binding site for V1 was clearly seen with this DNA fragment at the GGTACC sequence (results not shown). For trans-D1, two potential binding sites were identified: CAGTGA and GGCGAC.

\section{ESI-MS Evaluation of trans-D1 and cis-C1 Binding Sequences}

After identifying some possible specific binding sequences of cis-C1 and trans-D1 using DNAse I footprinting experiments, the binding of these ligands to DNA duplexes containing the most promising specific sequences were further evaluated by ESI-MS. Duplex ds1 contains the GGTACC sequence which is a potential specific binding site for cis-C1 and is the same sequence identified for V1, and duplex ds5 contains a possible specific binding sequence CAGTGA for transD1. The full sequences of these duplexes are shown in Table $^{\circ} 1 .^{\circ}$ Additional ${ }^{\circ}$ experiments $^{\circ}$ were $^{\circ}$ done $^{\circ}$ with $^{\circ} \mathrm{ds} 6$, which contains a second possible binding site for cis-C1, GGGCCC, and ds7, containing the second potential site for trans-D1, GGCGAT.

The mass spectrum acquired for a solution containing cis- $\mathbf{C 1}$ and ds1 at equimolar concentrations in 50 $\mathrm{mM}$ ammonium acetate with $25 \%$ methanol demonstrates that cis-C1 forms very abundant 1:1 complexes with $^{\circ}$ this $^{\circ}$ duplex $^{\circ}\left(\right.$ Figure $\left.^{\circ} 3 a\right) .{ }^{\circ}$ The $^{\circ}$ abundance $^{\circ}$ of ${ }^{\circ}$ the unbound DNA ions are very low, suggesting cis-C1 undergoes extensive complexation with this duplex. In addition, there are no complexes with a 2:1 binding stoichiometry, which is expected since the duplex con-
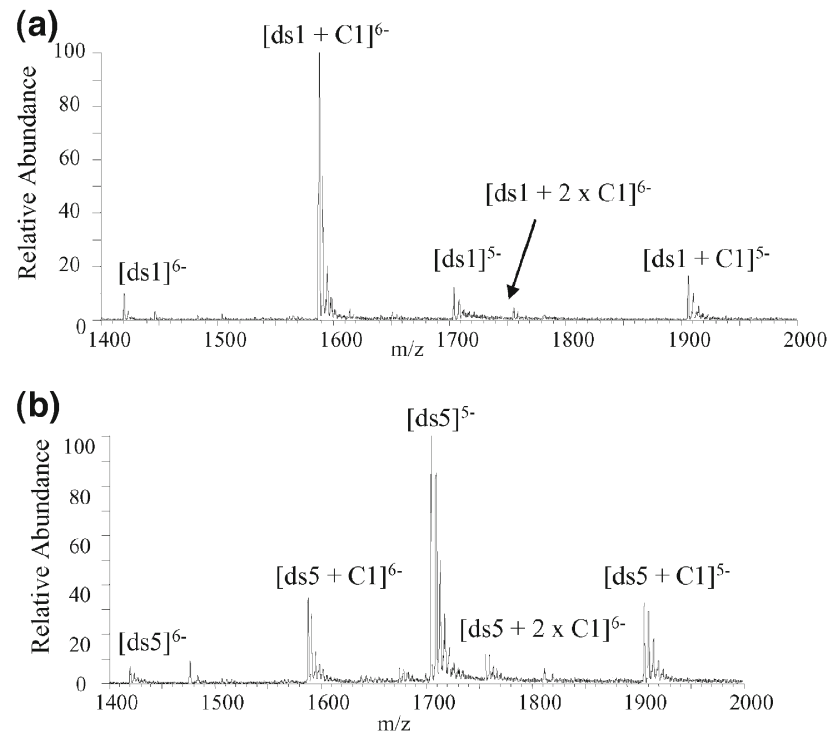

Figure 3. ESI mass spectra for complexes containing cis-C1 and equimolar $(10 \mu \mathrm{M})$ amounts of (a) ds1 days(GGGCGGTACCGCGG/CCGCGGTACCGCCC) and (b) ds5, d(GGGACAGTGAGGGG/CCCCTCACTGTCCC). 
tains a specific binding site in the center of this sequence. ${ }^{\circ}$ Based $^{\circ}$ on ${ }^{\circ}$ the ${ }^{\circ}$ abundances ${ }^{\circ}$ of ${ }^{\circ}$ the ${ }^{\circ}$ ions ${ }^{\circ}$ in ${ }^{\circ}$ Figure $3 a,{ }^{\circ}$ the ${ }^{\circ}$ fraction ${ }^{\circ}$ of ${ }^{\circ}$ bound ${ }^{\circ} \mathrm{DNA}^{\circ}{ }^{\circ}$ or ${ }^{\circ}$ the $^{\circ}$ solution ${ }^{\circ}$ of ${ }^{\circ} \mathrm{ds} 1$ with ${ }^{\circ}$ cis-C1 was $^{\circ}$ calculated $^{\circ}$ to $^{\circ}$ be $^{\circ} 0.86^{\circ}\left(\right.$ Table $\left.^{\circ} 2\right) .^{\circ}$ These results suggest that the binding of cis-C1 with ds1 is more extensive than the binding of $\mathbf{V 1}$ with the same duplex, as the fraction of bound DNA for V1 with the duplex (shown in Figure $1 \mathrm{~b}$ ) 'was found to be $0.66^{\circ}$ (Table 2). ${ }^{\circ}$ The ${ }^{\circ}$ higher ${ }^{\circ}$ binding $^{\circ}$ affinity $^{\circ}$ between ${ }^{\circ}$ cis- $\mathbf{C 1}$ and ${ }^{\circ}$ the GGTACC sequence was also demonstrated in the footprinting experiments discussed above. cis-C1 was also found to form complexes with ds6, which contained the GGGCCC binding site (spectra not shown). However, the fraction of bound DNA for cis-C1 and ds6 was 0.51, which suggests less extensive complexation between the cis-C1 and ds6 compared to ds1 and indicates a preference for the GGTACC binding sequence by the ligand.

Experiments aimed at evaluating the binding between cis-C1 and a DNA duplex that does not contain a target binding sequences were also undertaken. Duplex ds5 was selected for this experiment because the target binding sequence in the duplex, CAGTGA, was identified as a possible specific binding site for trans-D1 but not cis-C1. The ESI mass spectrum of a solution containing equimolar $(10 \mu \mathrm{M})$ concentrations of cis- $\mathbf{C} \mathbf{1}$ and ds5 is $^{\circ}$ shown $^{\circ}$ in $^{\circ}$ Figure $^{\circ} 3 b^{\circ} .^{\circ}$ The $^{\circ}$ extent $^{\circ}$ of $^{\circ}$ complexation between cis-C1 and the duplex is lower than what was observed in the spectra of solutions containing cis-C1 with $^{\circ} \mathrm{ds}^{\circ}\left(\text { Figure }^{\circ} 3 \mathrm{a}\right)^{\circ}$ and $^{\circ} \mathrm{ds}^{\circ}\left(\right.$ spectra $^{\circ}$ not $^{\circ}$ shown $) .^{\circ}$ In Figure $3 \mathrm{~b}$ the ${ }^{\circ}$ bundances ${ }^{\circ}$ of the ${ }^{\circ}$ unbound DNA ions ${ }^{\circ}$ are considerably greater than the abundance of the 1:1 complexes. The fraction of bound DNA was calculated to be 0.38 which is significantly lower than the fraction of bound DNA for cis-C1 with ds1 (0.86) and moderately lower than that of cis-C1 with ds6 (0.51). These results indicate cis- $\mathbf{C} \mathbf{1}$ forms more abundant complexes with ds1 and ds6 which is consistent with the specific binding site identified by DNAse I footprinting experiments.

Similar experiments were undertaken involving trans-D1 and ds5 and ds7, each which contain a possible specific binding site of the ligand (CAGTGA and GGCGAC, respectively) and ds1, which was identified as a specific binding site for cis-C1 but not trans-D1. The results of these experiments (spectra not shown) are summarized ${ }^{\circ}$ in Table 2 , and ${ }^{\circ}$ they ${ }^{\circ}$ suggest ${ }^{\circ}$ that ${ }^{\circ}$ while ${ }^{\circ}$ the structures of trans-D1 and cis-C1 are similar, they exhibit different binding behavior with the duplexes. The fraction of bound DNA in the spectrum of trans-D1 with ds5 was calculated to be 0.78 , which is much greater than the fraction of bound DNA of cis-C1 with the same duplex (0.38). trans-D1 also formed abundant complexes with ds7, as indicated by a fraction of bound DNA of 0.85 for the ligand with the duplex. Conversely, the fraction bound for ds1 with trans-D1 was only 0.41 compared to 0.86 observed with cis-C1.

As a further comparison, the fraction of bound DNA of V1 with ${ }^{\circ} \mathrm{ds} 1^{\circ}{ }^{\circ} s^{\circ}$ also $^{\circ}$ summarized $^{\circ}{ }^{\circ}{ }^{\circ}$ Table $^{\circ} 2^{\circ}$ since $^{\circ} \mathbf{V 1}$ and cis- $\mathbf{C} \mathbf{1}$ have the same possible specific binding sequence. The 0.66 value for fraction bound is not as great as that observed with cis-C1, suggesting cis-C1 might be an improvement over V1 in terms of forming abundant complexes with the GGTACC sequence. The fraction of bound DNA in a spectrum of V1 with ds5, a duplex that does not contain a specific binding site for $\mathbf{V 1}$, is 0.52 which is lower than that with ds1. However, the difference in the fraction of bound DNA for V1 with ds1 (containing the specific binding sequence) and ds5 (no specific binding sequence) is not as great as that observed with cis-C1. These results indicate that cis-C1 shows the most promising selectivity for binding to its target sequences over other sequences and demonstrate that the relative binding behavior of the bis-intercalators observed by ESI-MS correlates with DNAase I footprinting results.

Because NDI1 contains only one intercalating unit and lacks the scaffold designed to interact with the groove of duplex DNA, this compound functions as a mono-intercalator and was used as a reference ligand to compare its complexation with the same duplexes as used in the experiments above for cis-C1 and trans-D1. The ESI-mass spectra indicate the formation of 1:1 and 2:1 NDI1:duplex complexes, with the fractions bound for ${ }^{\circ} \mathrm{ds}^{\circ}$ and $^{\circ} \mathrm{ds}^{\circ}$ summarized $^{\circ}$ in $^{\circ} \mathrm{Table}^{\circ} 2 .^{\circ}$ The $^{\circ}$ greater abundances of the 2:1 NDI1:duplex complexes is consistent with a lower specificity of NDI1.

\section{Concentration Dependent Binding of trans-D1 and cis-C1}

To further explore how the complexation of trans-D1 and cis- $\mathbf{C} \mathbf{1}$ changes with ligand/DNA molar ratios, concentration dependent binding was assessed. A series of solutions containing trans-D1 or cis-C1 with a duplex containing a proposed specific binding site (ds5 for trans-D1 and ds1 for cis-C1) were prepared with a DNA concentration of 10 $\mu \mathrm{M}$ and a variable ligand concentration of $2.5,5.0,10$, or 20 $\mu \mathrm{M}$. The mass spectra of trans-D1 with ds 5 at these molar ratios demonstrate that when the ligand concentration is increased relative to the DNA concentration, changes in the extent of ligand complexation are observed in the mass spectra. At a trans-D1/ds5 M ratio of 0.25, complexes with 1:1 binding stoichiometry are present, but with low relative abundances compared with the unbound DNA ions. As the molar ratio is increased to 0.5 , the relative abundance of the 1:1 complexes increases, and low abundance 2:1 complexes emerge while the abundance of the free DNA decreases. When the molar ratio is increased to $1: 1$ or even $2: 1$, the abundances of the $2: 1$ complexes increase further, while the abundance of the unbound DNA ions diminish.

The appearance of the 2:1 complexes at higher trans$\mathrm{D} 1 / \mathrm{ds} 5 \mathrm{M}$ ratios is notable since ds5 contains only one relatively high affinity binding site for trans-D1. The results imply that trans-D1 is able to bind to the DNA duplex in a non-specific manner when the ligand concentration is increased relative to the DNA. At this point, it is 
(a)

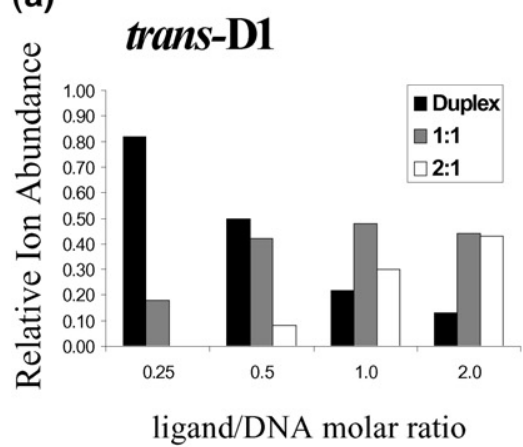

(b)

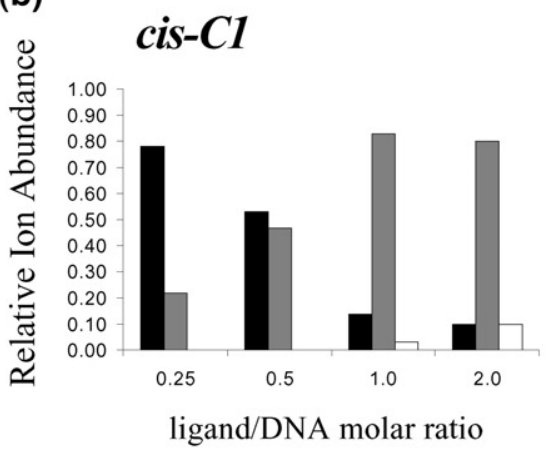

(c)

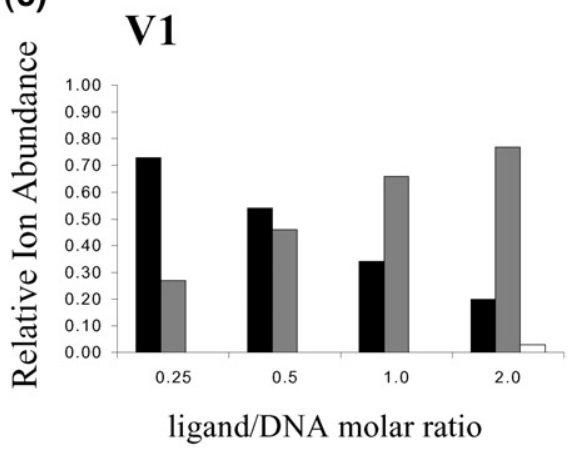

Figure 4. Summary plots of concentration dependent binding studies of (a) trans-D1 with ds5, (b) cis-C1 with ds1, and (c) V1 with ds1, indicating distribution of free duplexes, 1:1 ligand:duplex complexes, and 2:1 ligand:duplex complexes. Solutions contained the specified duplex DNA at $10 \mu \mathrm{M}$ and ligand at $2.5 \mu \mathrm{M}, 5.0 \mu \mathrm{M}, 10 \mu \mathrm{M}$, and $20 \mu \mathrm{M}$.

unknown how the 2:1 complexes are formed, but some possible scenarios include that the ligand may bind to the DNA via the intercalation of only one of the NDI units, two trans-D1 ligands could be aggregating in solution and then binding to the DNA duplex, the second ligand may non-specifically aggregate to the DNA, or there could be two binding sites on the duplex that are mutually exclusive. This last scenario is the least likely since the duplex contains one proposed specific binding site at the center of the sequence and the ligand bound at the higher affinity site would hinder the binding of the second molecule. The presence of D1 footprints that are less than six bases long in $^{\circ}$ Figure $^{\circ} 2^{\circ}$ suggest $^{\circ}$ the ${ }^{\circ}$ ligand ${ }^{\circ}$ is ${ }^{\circ}$ able ${ }^{\circ}$ to ${ }^{\circ}$ partially ${ }^{\circ}$ bind ${ }^{\circ}$ to the duplex via one NDI unit. Future NMR modeling work will shed light on the structure of these higher binding stoichiometry complexes.

The results of the concentration dependent binding studies for trans-D1 with ds5, cis-C1 with ds1 (spectra not shown), and V1 with ds1 (discussed earlier) are summarized by the graphs in Figure 4 , which ${ }^{\circ}$ reflect the relative ion abundance of the unbound duplex ions (black bars), 1:1 complexes (grey bars), and 2:1 complexes (light bars), grouped by ligand/DNA ratio. The results for cis-C1 with ds1 are significantly different from those of trans-D1 with ds5. As the ligand molar ratio is increased, the relative ion abundance of the free DNA duplex decreases and the abundances of the 1:1 complexes increase. However, when there is excess cis-C1 in solution, the 1:1 binding stoichiometry is dominant and only very low abundance 2:1 complexes are observed. The results of cis-C1 with ds1 are similar

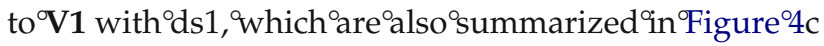
and suggest that like V1, cis-C1 is binding specifically to the DNA duplex that contains a target site.

\section{ESI-MS/MS Studies of Complexes Containing V1, trans-D1, and cis-C1}

An additional goal of this study was to determine if a bis-intercalative binding mode could be distinguished from a mono-intercalative binding mode using CAD since full scan mass spectra provide little insight into binding interactions between ligands and DNA. Until now, no MS/MS studies have been done on complexes

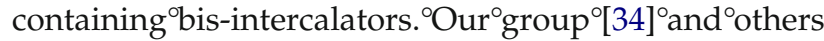
$\left[12,{ }^{\circ} 35\right]^{\circ}$ have $^{\circ}$ used $^{\circ}$ collisional $^{\circ}$ activated $^{\circ}$ dissociation experiments to examine the fragmentation patterns of intercalator/DNA complexes, including complexes of actinomycin- $\mathrm{D}^{\circ}\left[12,{ }^{\circ} 35\right],{ }^{\circ}$ daunomycin ${ }^{\circ}[34],{ }^{\circ}$ and ${ }^{\circ}$ nogala$\operatorname{mycin}^{\circ}[34] .{ }^{\circ}$ For $^{\circ} \operatorname{complexes}^{\circ}$ containing $^{\circ}$ actinomycin-D, the predominant dissociation route is loss of the drug, but some strand separation (with retention of actinomycin D by one strand) and some nucleobase loss are also observed $^{\circ}$ to $^{\circ} \mathrm{a}^{\circ}$ lesser $^{\circ}$ extent $^{\circ}\left[12,{ }^{\circ} 35\right] . .^{\circ}$ Our $^{\circ}$ own $^{\circ}$ CAD results for duplex/actinomycin-D complexes confirm that the primary fragmentation route is the disruption of the non-covalent interactions between actinomycin-D and the duplex, resulting in loss of actinomycin-D. Our earlier studies of complexes containing daunomycin or nogalamycin in a quadrupole ion trap mass spectrometer indicated that the drug/DNA complexes followed charge ${ }^{\circ}$ state $^{\circ}$ dependent ${ }^{\circ}$ fragmentation ${ }^{\circ}$ patterns ${ }^{\circ}[34] .^{\circ} \mathrm{At}$ lower charge states, the dominant fragmentation pathway was ejection of the drug leaving the intact duplex, while at higher charge states, separation of the individual single strand components of the duplex occurred, leaving the drug bound to one of the single strands. Dissociation by cleavage of a nucleobase was insignificant or not observed for complexes containing daunomycin ${ }^{\circ}{ }^{\circ}$ nogalamycin $[34]^{\circ}{ }^{\circ} \mathrm{CAD}^{\circ}$ of $^{\circ} \mathrm{Complexe}^{\circ} \mathrm{Contain}-$ ing $^{\circ}$ reference $^{\circ}$ ligand $^{\circ}$ NDI1 [27],, $\mathrm{a}^{\circ}$ mono-intercalator, resulted in fragmentation patterns consistent with those obtained for the daunomycin and nogalamycin complexes described above (spectra not shown). Complexes in the 5- charge state dissociated via loss of a neutral NDI1 ligand, while complexes in the 6- charge state produced fragment ions resulting from ligand ejection and predominant strand scission (spectra not shown).

CAD experiments were undertaken in the present study to examine what, if any, differences exist in the fragmentation pathways of complexes containing V1, trans-D1, and cis-C1 compared to the mono-intercala- 

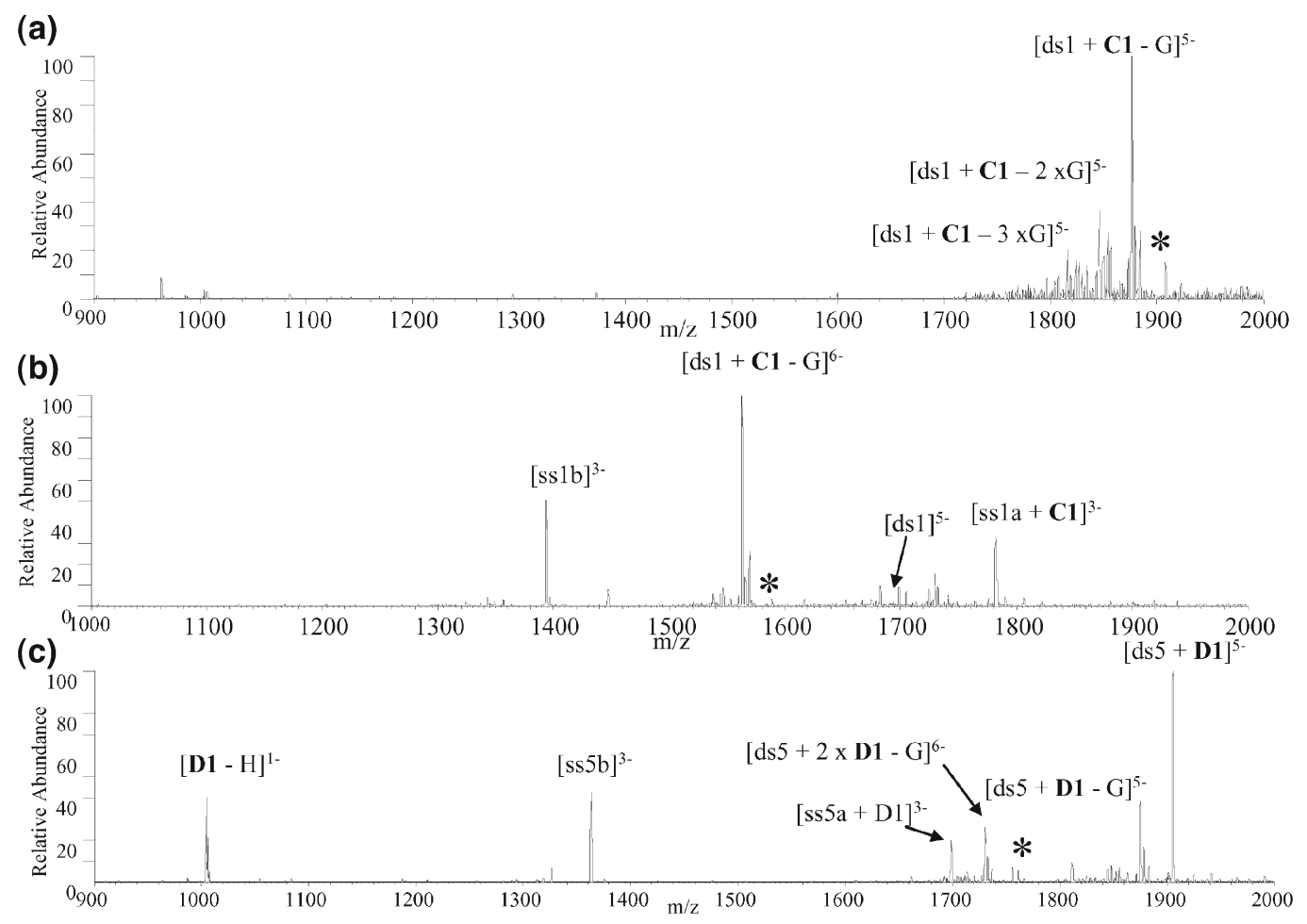

Figure 5. CAD mass spectra of (a) $[\mathrm{ds} 1+c i s-\mathrm{C} 1]^{5-},(\mathbf{b})[\mathrm{ds} 1+c i s-\mathrm{C} 1]^{6-}$, and (c) $[\mathrm{d} s 5+2 \times$ trans-D1 $]^{6-}$. The precursor ion is indicated by the asterisk. Solutions contained equimolar concentrations $(10 \mu \mathrm{M})$ of the ligand and DNA duplex.

tors. The low charge state $[\mathrm{ds}+\mathrm{L}]^{5-}$ complexes, where $\mathrm{L}$ represents either $\mathbf{V} \mathbf{1}$, cis- $\mathbf{C} \mathbf{1}$, or trans-D1, produced the same fragmentation pattern, characterized by the guanine $^{\circ}$ nucleobase ${ }^{\circ}$ loss $^{\circ}\left(\right.$ Figure $^{\circ} 5$ a).$^{\circ}$ This $^{\circ}$ fragmentation pattern is different from what is commonly observed for the complexes containing commercial mono-intercalators, which predominantly dissociate via ejection of the ${ }^{\circ}$ ligand ${ }^{\circ}\left[12,{ }^{\circ} 35\right]^{\circ}{ }^{\circ}$ For $^{\circ} \mathbf{V 1}{ }^{\circ}{ }^{\circ}$ trans-D1 and $^{\circ}$ cis-C1, ${ }^{\circ}$ all ${ }^{\circ} 1: 1$ complexes in the 6- charge state dissociated via dominant guanine nucleobase loss in addition to strand scission, with the ligand remaining bound to a single strand as demonstrated by the CAD spectrum of [ds1 + C1 $]^{6-}{ }^{\circ}$ shown $^{\circ}$ in ${ }^{\circ}$ Figure $^{\circ} 5 b^{\circ} .^{\circ}$ There $^{\circ}$ were $^{\circ}$ also $^{\circ}$ very ${ }^{\circ}$ low abundance ions resulting from ejection of the negatively charged ligand, leaving the intact duplex. The predominance of nucleobase loss rather than ligand ejection of the 1:1 complexes in the 5- and 6- charge states is indicative of stronger binding interactions between the bis-intercalators and duplex DNA compared to traditional mono-intercalators, resulting from two intercalation sites and specific hydrogen bonding interactions between the scaffold and the DNA grooves. It is interesting that the strand scission pathway occurs in such a way that the ligand remains bound exclusively to only

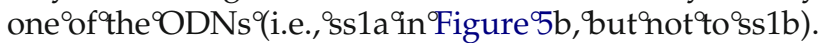
Although ss1a is more G-rich than ss1b, the underlying reason for this ODN selectivity is not clear.

The 2:1 complexes in the 6- charge state produced a different CAD pattern than those described above for the 1:1 complexes. Trans-D1 was the only compound to form 2:1 complexes with sufficient abundance for CAD experiments, and the resulting CAD mass spectrum of $\left[\mathrm{ds} 5^{\circ}+{ }^{\circ} 2^{\circ} \times \mathrm{D} 1\right]^{6-{ }^{\circ}}$ is $^{\circ}$ shown $^{\circ}$ in $^{\circ}$ Figure $^{\circ} 5 \mathrm{c}^{\circ}{ }^{\circ}$ The ${ }^{\circ}$ most abundant product ion results from ejection of the negatively charged ligand, leaving the $[\mathrm{ds} 5+\mathrm{D} 1]^{5-}$ complex. Ions resulting from strand scission and guanine base loss ions from the precursor complex are present but with significantly lower abundances. This result suggests that the second molecule is bound differently (and likely more weakly) than the first ligand in the 2:1 complexes which is similar to what has been previously observed ${ }^{\circ}$ with $^{\circ}{ }^{\circ}$ omplexes ${ }^{\circ}$ containing ${ }^{\circ}$ nogalamycin ${ }^{\circ}[34]$. Furthermore, the duplex DNA used in these experiments contain only one specific binding site for the ligands, so the presence of the 2:1 complexes indicates some non-specific binding by the second ligand, which is expected to be a weaker binding interaction.

All complexes in the 7- charge state, regardless of binding stoichiometry, dissociated by strand scission leaving the ligands bound to a single strand (spectra not shown). This fragmentation pattern is consistent with past $^{\circ} \mathrm{CAD}^{\circ}$ studies ${ }^{\circ}$ involving $^{\circ}$ intercalators ${ }^{\circ}[34]^{\circ}$ and $^{\circ}$ is believed to result from coulombic repulsion of the more highly charged phosphate backbones.

The CAD fragmentation patterns of complexes containing echinomycin (Scheme 1) with duplex DNA were also evaluated in this study to serve as a comparison to the results of the new bis-intercalators. Echinomycin has been found to bind to duplex DNA via bis-intercalation, with the two quinoxaline rings preferably inter- 
calating at $\mathrm{CpG}$ sites, and the bicyclic peptide scaffold oriented toward the DNA minor groove where hydrogen bonds are formed between the peptide and the nucleobases. In general, little ligand ejection was observed in the CAD spectra. Complexes in the 5- charge state undergo guanine base loss upon collisional activation. Guanine nucleobase loss is also observed in the CAD spectra of all complexes in the 6- charge state, in addition to ions resulting from strand scission. Complexes in the 7- charge state dissociated by strand separation. The CAD spectra of complexes containing echinomycin are similar to those containing V1, trans$\mathrm{D} 1$, or cis-C1, and are markedly different than those of the complexes containing mono-intercalators.

\section{Single Strand Binding of V1, trans-D1, and cis-C1}

The bis-intercalators evaluated in this study were designed to engage in two primary types of binding interactions with duplex DNA: intercalation interactions between the NDI units and the nucleobases, and hydrogen bonding interactions between the peptide scaffold and the minor or major groove of the DNA duplex. To determine if the ligands bind selectively to duplex DNA via these interactions over other DNA structures, ESI-MS was used to analyze solutions of trans-D1 or cis-C1 with single strand DNA. The single strand ODNs used for these experiments, d(GGGCGGTACCGCGG) (ss1) and d(GGGACAGTGAGGGG) (ss5), were one of the two complementary single strand ODNs used to anneal duplexes ds1 and ds5, respectively. Based on the results of the duplex DNA binding studies of the ligands discussed above, cis-C1 formed the most abundant complexes with ds1 so the binding of cis-C1 to ss1 was evaluated, while trans-D1 formed more abundant complexes with ds5, so ss5 was used. Using these single strand ODNs ensures that the same target binding sequences present in the duplexes are also found in the single strand sequences.

Solutions containing one single strand ODN and either V1, trans-D1 or cis-C1 at equimolar $10 \mu \mathrm{M}$ concentration in ammonium acetate/methanol buffer were prepared and analyzed using the same instrument conditions used in experiments involving the duplex DNA discussed above. While cis-C1 and V1 did not form any complexes with ss1, trans-D1 formed low abundance ligand/DNA complexes with ss5 (spectra not shown). The results of the single strand binding study are summarized by the fraction of bound DNA values ${ }^{\circ}$ shown ${ }^{\circ}$ in Table 2. In $^{\circ}$ general, ${ }^{\circ}$ the ${ }^{\circ}$ complexes ${ }^{\circ}$ that formed between the trans-D1 and the single strand DNA were relatively low in abundance compared to ligand $/$ duplex $^{\circ} \mathrm{DNA}^{\circ} \mathrm{Complexes}^{\circ}\left(\mathrm{Table}^{\circ} 2\right)$, ${ }^{\circ}$ suggesting that the ligand prefers binding to duplex DNA. It is also interesting to note that trans-D1 is less selective for duplex DNA compared to cis-C1, which echoes the earlier observation that trans-D1 exhibited considerable concentration dependent binding behavior with the duplex DNA and formed non-specific 2:1 complexes.

\section{Conclusions}

The utility of ESI-MS as a tool for screening noncovalent complexes formed between threading bis-intercalators and DNA is demonstrated in this study. Binding stoichiometries and ligand sequence selectivity can be quickly assessed and qualitatively compared using the ESI-mass spectra, while CAD experiments provide information about ligand binding interactions. Our results demonstrated that V1 forms abundant 1:1 complexes with ds1, the duplex containing its specific binding sequence $5^{\prime}$-GGTACC- $3^{\prime}$, and forms more abundant complexes with ds1 over ds5, which does not contain the specific binding sequence of the ligand. These results correlate well with previous DNAse I footprinting and NMR studies. Experiments involving trans-D1 indicate the ligand extensively binds to duplex ds 5 containing the target sequence $5^{\prime}$-CAGTGA- $3^{\prime}$ and forms significantly less abundant complexes with ds1, which does not contain a specific binding site identified by footprinting experiments. However, at higher ligand/DNA molar ratios, trans-D1 forms 2:1 complexes which is indicative of non-specific binding by the ligand. Cis-C1 exhibited the most promising specific binding behavior to ds 1 containing the $5^{\prime}$-GGTACC-3' target sequence as evidenced by the formation of significantly more abundant complexes with this duplex over ds5 which did not contain a specific binding site. Unlike trans-D1, cis-C1 did not form extensive 2:1 complexes at ligand/DNA molar ratios greater than one, conveying that the cis structure of $\mathbf{C 1}$ is favorable for more specific binding.

In general, the CAD spectra of the bis-intercalators are characterized by dominant guanine base loss in the 5- and 6- charge states, with increasing degrees of strand scission as the charge state increases. The different CAD fragmentation patterns exhibited by the bis-intercalator/duplex complexes compared with complexes containing known mono-intercalators mirror the shift in binding interaction of the ligands, characterized by intercalation at two sites and hydrogen bonding interactions with the DNA major or minor groove.

\section{Acknowledgments}

Funding from the Robert A. Welch Foundation (F1155 to JSB) and the National Institutes of Health (RO1 GM65956 to JSB and GM069647 to BLI) is gratefully acknowledged.

\section{References}

1. Goodman, L. S.; Hardman, J. G.; Limbird, L. E.; Gilman, A. G. Goodman and Gilman's the Pharmacological Basis of Therapeutics, 10th ed.; McGrawHill: New York, 2001, pp 1381-1460.

2. Propst, C. L.; Perun, T. J. Nucleic Acid Targeted Drug Design; Marcel Dekker: New York, 1992, pp 1-12.

3. Hofstadler, S. A.; Griffey, R. H. Analysis of Noncovalent Complexes of DNA and RNA by Mass Spectrometry. Chem. Rev. 2001, 101, 377-390.

4. Beck, J. L.; Colgrave, M. L.; Ralph, S. F.; Sheil, M. M. Electrospray Ionization Mass Spectrometry of Oligonucleotide Complexes with Drugs, Metals, and Proteins. Mass Spectrom. Rev. 2001, 20, 61-87. 
5. Brana, M. F.; Cacho, M.; Gradillas, A.; de Pascual-Teresa, B.; Ramos, A. Intercalators as Anticancer Drugs. Curr. Pharm. Des. 2001, 7, 1745-1780.

6. Triolo, A.; Arcamone, F. M.; Raffaelli, A.; Salvadori, P. Noncovalent Complexes Between DNA-Binding Drugs and Doubly Stranded Deoxyoligonucleotides: A study by Ionspray Mass Spectrometry. J. Mass Spectrom. 1997, 32, 1186-1194.

7. Kapur, A.; Beck, J. L.; Sheil, M. M. Observation of Daunomycin and Nogalamycin Complexes with Duplex DNA Using Electrospray Ionization Mass Spectrometry. Rapid Commun. Mass Spectrom. 1999, 13, 24892497.

8. Gupta, R.; Kapur, A.; Beck, J. L.; Sheil, M. M. Positive Ion Electrospray Ionization Mass Spectrometry of Double Stranded DNA/Drug Complexes. Rapid Commun. Mass Spectrom. 2001, 15, 2472-2480.

9. Colgrave, M. L.; Beck, J. L.; Sheil, M. M.; Searle, M. S. Electrospray Ionization Mass Spectrometric Detection of Weak Noncovalent Interactions in Nogalamycin-DNA Complexes. Chem. Commun. 2002, 6, 556557.

10. Furlan, R. L. A.; Watt, S. J.; Garrido, L. M.; Amarante-Mendes, G. P.; Nur-E-Alam, M.; Rohr, J.; Brana, A.; Mendez, C.; Salas, J. A.; Sheil, M. M.; Beck, J. L.; Padilla, G. DNA-Binding Properties of Cosmomycin D, an Anthracycline with Two Trisaccharide Chains. J. Antibiot. 2004, 57, 647-654.

11. Urathamakul, T.; Beck, J. L.; Sheil, M. M.; Aldrich-Wright, J. R.; Ralph, S. F. A Mass Spectrometric Investigation of Noncovalent Interactions Between Ruthenium Complexes and DNA. Dalton Trans. 2004, 17, 2683-2690.

12. Wan, K. X.; Gross, M. L.; Shibue, T. Gas-Phase Stability of DoubleStranded Oligodeoxynucleotides and Their Noncovalent Complexes with DNA-Binding Drugs as Revealed by Collisional Activation in an Ion Trap. J. Am. Soc. Mass Spectrom. 2000, 11, 450-457.

13. Wan, K. X.; Shibue, T.; Gross, M. L. Noncovalent Complexes Between DNA-Binding Drugs and Double Stranded Oligodeoxynucleotides: A Study by ESI Ion Trap Mass Spectrometry. J. Am. Chem. Soc. 2000, 122, 300-307.

14. Beck, J. L.; Gupta, R.; Urathamakul, T.; Williamson, N. L.; Sheil, M. M.; Aldrich-Wright, J. R.; Ralph, S. F. Probing DNA Selectivity of Ruthenium Metallointercalators Using ESI Mass Spectrometry. Chem. Commun. 2003, 5, 626-627.

15. Gupta, R.; Beck, J. L.; Ralph, S. F.; Sheil, M. M.; Aldrich-Wright, J. R. Comparison of the Binding Stoichiometries of Positively Charged DNA-Binding Drugs Using Positive and Negative Ion Electrospray Ionization Mass Spectrometry. J. Am. Soc. Mass Spectrom. 2004, 15, 1382-1391.

16. Gabelica, V.; De Pauw, E.; Rosu, F. Interaction Between Antitumor Drugs and a Double Stranded Oligonucleotide Studied by Electrospray Ionization Mass Spectrometry. I. Mass Spectrom. 1999, 34, 1328-1337.

17. Greig, M. J.; Robinson, J. M. Detection of oligonucleotide-ligand complexes by ESI-MS (DOLCE-MS) as a component of high throughput screening. J. Biomol. Screen. 2000, 5, 441-454.

18. Rosu, F.; De Pauw, E.; Guittat, L.; Alberti, P.; Lacroix, L.; Mailliet, P.; Riou, J. F.; Mergny, J. L. Selective Interaction of Ethidium Derivatives with Quadruplexes: An Equilibrium Dialysis and Electrospray Ionization Mass Spectrometry Analysis. Biochemistry 2003, 42, 10361-10371.
19. Reyzer, M. L.; Brodbelt, J. S.; Kerwin, S. M.; Kumar, D. Evaluation of Complexation of Metal-Mediated DNA-Binding Drugs to Oligonucleotides via Electrospray Ionization Mass Spectrometry. Nucleic Acids Res. 2001, 29, e103.

20. Carrasco, C.; Rosu, F.; Gabelica, V.; Houssier, C.; De Pauw, E.; GarbayJaureguiberry, C.; Roques, B.; Wilson, W. D.; Chaires, J. B.; Waring, M. J.; Bailly, C. Tight Binding of the Anticancer Drug Ditercalinium to Quadruplex DNA. Chem. Biochem. 2002, 3, 1235-1241.

21. Lokey, R. S.; Kwok, Y.; Guelev, V.; Pursell, C. J.; Hurley, L. H.; Iverson, B. L. A New Class of Polyintercalating Molecules. J. Am. Chem. Soc. 1997, $119,7202-7210$

22. Lee, J.; Guelev, V.; Sorey, S. Hoffman, D. W.; Iverson, B. L. NMR Structural Analysis of a Modular Threading Tetraintercalator Bound to DNA. J. Am. Chem. Soc. 2004, 126, 14036-14042.

23. Guelev, V.; Lee, J.; Ward, J.; Sorey, S.; Hoffman, D. W.; Iverson, B. L. Peptide bis-Intercalator binds DNA via Threading Mode with Sequence Specific Contacts in the Major Groove. Chem. Biol. 2001, 8, 415-425.

24. Guelev, V.; Sorey, S.; Hoffman, D. W.; Iverson, B. L. Changing DNA Grooves A 1,4,5,8-Naphthalene Tetracarboxylic Diimides bis-Intercalator with the Linker $(\beta \text {-Ala })_{3}$-Lys in the Minor Groove. J. Am. Chem. Soc. 2002, 124, 2864-2865.

25. Chu, Y.; Lynch, V.; Iverson, B. L. Synthesis and DNA Binding Studies of bis-Intercalators with a Novel Spiro-Cyclic Linker. Tetrahedron 2006, 62, $5536-5548$

26. Guelev, V. M.; Cubberley, M. S.; Murr, M. M.; Lokey, R. S.; Iverson, B. L. Design, Synthesis, and Characterization of Polyintercalating Ligands. Methods Enzymol. 2001, 340, 556-570.

27. Cubberley, M. S.; Iverson, B. L. ${ }^{1} \mathrm{H}$ NMR Investigation of Solvent Effects in Aromatic Stacking Interactions. J. Am. Chem. Soc. 2001, 123, 7560 7563.

28. Sambrook, J.; Russell, D. W. Molecular Cloning: A Laboratory Manual, 3rd ed.; Cold Spring Harbor Laboratory Press: Cold Spring Harbor, NY, 2001, pp 5.4-5.86.

29. Guelev, V. Ph.D. Thesis, University of Texas at Austin, 2002

30. Rueda, M.; Luque, F. J.; Orozco, M. Nature of Minor Groove BindersDNA Complexes in the Gas Phase. J. Am. Chem. Soc. 2005, 127, 11690-11698.

31. Gidden, J.; Ferzoco, A.; Baker, E. S.; Bowers, M. T. Duplex Formation and the Onset of Helicity in Poly d $(\mathrm{CG})_{\mathrm{n}}$ Oligonucleotides in a SolventFree Environment. J. Am. Chem. Soc. 2004, 126, 15132-15140.

32. Mazzitelli, C. L.; Kern, J. T.; Rodriguez, M.; Brodbelt, J. S.; Kerwin, S. M. Evaluation of Binding of Perylene Diimide and Benzannulated Perylene Diimide Ligands to DNA by Electrospray Ionization Mass Spectrometry. J. Am. Soc. Mass Spectrom. 2006, 17, 593-604.

33. Liu, Z.-R.; Hecker, K. H.; Rill, R. L. Selective DNA Binding of (NAlkylamine)-Substituted Naphthalene Imides and Diimides to $\mathrm{G}+$ C-rich DNA. J. Biomol. Struct. Dynam. 1996, 14, 331-339.

34. Keller, K. M.; Zhang, J. M.; Oehlers, L.; Brodbelt, J. S. Influence of Initial Charge State on Fragmentation Patterns for Noncovalent Drug/DNA Duplex Complexes. J. Mass Spectrom. 2005, 40, 1362-1371.

35. Gabelica, V.; De Pauw, E. Comparison of the Collision-Induced Dissociation of Duplex DNA at Different Collision Regimes: Evidence for a Multistep Dissociation Mechanism. J. Am. Soc. Mass Spectrom. 2002, 13, 91-98. 